PALABRAS CLAVE

Desarrollo económico

Innovaciones tecnológicas

Desarrollo industrial

Industrias de exportación

Recursos naturales

Competitividad

Tecnología de la información

Tecnología de las comunicaciones

Organización industrial

América Latina
Carlota Pérez

Investigadora asociada, Centro

de Análisis y Políticas/Centro de

Investigación sobre Finanzas (CFAP/

CERF), Escuela de Negocios Judge,

Universidad de Cambridge, R.U.;

Catedrática de Tecnología y Desarrollo,

Universidad Tecnológica de Talín,

Estonia; Investigadora Honorífica,

Science and Technology Policy Research

(SPRU), Universidad de Sussex, R.U.

carperezperez@yahoo.com
REVISTA CEPAL 100 - ABRIL 2010

\section{Dinamismo tecnológico e inclu- sión social en América Latina: una estrategia de desarrollo productivo basada en los recursos naturales}

\author{
Carlota Pérez
}

$\mathrm{E}$

este trabajo se propone una estrategia para dinamizar el desarrollo en América Latina aprovechando las oportunidades específicas del contexto actual y las ventajas que ofrece la región. Se analizan brevemente las características de la globalización y los rasgos del paradigma tecnoeconómico de la revolución de las tecnologías de la información y las comunicaciones (TIC), para definir las nuevas posibilidades de mercado, de posicionamiento en redes globales y de opciones tecnológicas. Desde esa perspectiva, se identifican las industrias de procesos basadas en recursos naturales como un espacio complementario con la especialización de Asia en industrias de ensamblaje. Dada la baja tasa de empleo de aquellas industrias, se propone una estrategia dual para promover también la creación de riqueza "desde abajo", aprovechando la nueva flexibilidad en diversidad tecnológica, transporte y comercio. El propósito es estimular el debate y la experimentación en políticas y señalar direcciones de investigación al respecto. 


\section{I}

\section{Introducción}

En el presente trabajo se examinan las tendencias actuales de la globalización y la difusión tanto de la revolución de las tecnologías de la información y las comunicaciones (TIC) como de su paradigma, a fin de proponer una visión de futuro exitosa y socialmente equitativa para América Latina, una visión basada en rasgos compartidos y capaz de abarcar al mismo tiempo toda la diversidad de sus países. Con ello se espera proporcionar los fundamentos para la realización de investigaciones ulteriores profundas, así como promover un debate serio y amplio alrededor del tema.

La propuesta se organiza sobre la base del trabajo de la autora acerca de la difusión de las revoluciones tecnológicas, la manera como las tecnologías y las capacidades tecnológicas determinan el potencial de crecimiento y el modo como los contextos tecnológicos mundiales cambian las ventanas de oportunidades para el desarrollo de países y regiones.

Los crecientes precios de las materias primas a mediados de la década de 2000 sin duda ofrecieron el impulso para retomar un ritmo mayor de crecimiento, pero las capacidades tecnológicas no crecieron al mismo ritmo y aún persisten desigualdades muy profundas, más hondas incluso que en el decenio de 1970. La región está tomando conciencia de la necesidad de contar con bases más sólidas para llegar a tener una fuente más estable de crecimiento económico y de potencial para el desarrollo social.

Dado el fuerte sesgo asiático del actual proceso de globalización, es muy importante identificar áreas con potencial tecnológico donde América Latina tenga una ventaja comparativa respecto de Asia. En términos bastante simplificados, Asia se puede considerar como un continente muy densamente poblado, con una dotación relativamente escasa de recursos naturales. América Latina, en cambio, es muy rica en recursos naturales y tiene una densidad poblacional mucho menor. Estas condiciones le dan a Asia la ventaja en cuanto a las industrias de fabricación (ensamblaje) intensivas en mano de obra, mientras las de América Latina favorecen a las industrias de procesos basadas en recursos naturales. Como la región es extremadamente diversa en cuanto

$\square$ Este artículo se basa en un trabajo preparado para el Programa de Política Tecnológica y Desarrollo de América Latina de la CEPAL. a la dotación de esos recursos, esta dirección general podría permitir $-\mathrm{y}$ de hecho requiere- especializaciones diferenciadas.

La adquisición de capacidades en las industrias basadas en recursos naturales, vinculadas a la biotecnología y a la ciencia de los materiales, tiene la ventaja de preparar el terreno para el posicionamiento adecuado en las tecnologías que hoy se vislumbran como probables protagonistas de la próxima revolución tecnológica: biotecnología, nanotecnología, bioelectrónica y nuevos materiales. Aunque será necesario un esfuerzo focalizado para asegurar que esa preparación tenga lugar.

Por otra parte, las industrias de procesos no son comúnmente intensivas en mano de obra y tienden a requerir una alta proporción de personal de mediana y alta calificación. Esto significa que aunque puedan contribuir al crecimiento económico y al enriquecimiento en cuanto al capital humano y técnico - ambos cruciales para dar un salto adelante en el desarrollo-, no son suficientes para reducir el abismo entre ricos y pobres, ni para eliminar el desempleo y superar la pobreza. Tampoco se puede confiar en el "efecto de filtración" (trickle down) tan cuestionado por la experiencia histórica. Esto sugiere la necesidad de emprender acciones en favor del desarrollo en dos direcciones: "desde arriba" y "desde abajo". Por lo tanto, esta propuesta supone lo que podría llamarse un "modelo dual integrado".

La mitad de la estrategia de desarrollo a promover "desde arriba" apuntaría a lograr la competitividad en los mercados mundiales para llegar a la frontera tecnológica en ciertas áreas y procesos e incluso tomar la delantera, a veces mediante alianzas con empresas globales. Por su parte, la mitad de la estrategia "desde abajo" implicaría actuar directamente en cada porción del territorio, en los niveles municipal y local, identificando, promoviendo, facilitando y apoyando las actividades de creación de riqueza dirigidas al mercado más adecuado: local o regional, nacional o global. Estas tenderán a ser aglomeraciones productivas (clusters) especializadas dirigidas a mercados de nicho basados en las ventajas locales.

Como se discutirá más adelante, las dos mitades de la estrategia dual son facilitadas por las nuevas condiciones globales. La acción "desde abajo" se dedicaría a la reducción de la pobreza y la acción "desde arriba" a la activación y fortalecimiento de los motores de 
crecimiento de la economía, con lo que proporcionaría los recursos para hacer viables ambas mitades.

La estrategia dual no puede ser implementada exclusivamente por el mercado, pero tampoco puede ser impuesta eficazmente por el gobierno, mucho menos en el paradigma actual, que requiere innovación constante y flexibilidad ante los cambios en el contexto. Este modelo solo puede funcionar adecuadamente como resultado de una visión compartida socialmente, donde los diversos agentes de cambio actúen de manera autónoma en las direcciones acordadas, integrados por un gobierno activo con un marco institucional adecuado y efectivo. $\mathrm{Su}$ implementación requerirá un proceso de construcción de consensos donde se involucre a las empresas, el gobierno, las universidades, los medios de comunicación y la sociedad en general, seguido por las medidas políticas adecuadas para inducir y facilitar el comportamiento del mercado en las direcciones acordadas.

La premisa de toda esta interpretación - y la del artículo en su totalidad - es la condición de suma positiva de todas las estrategias de desarrollo exitosas (con la excepción de los países que compiten por el liderazgo en los primeros lugares). Las transformaciones tecnológicas y económicas de los países centrales del sistema mundial y de las corporaciones líderes de las principales industrias determinan el contexto donde tienen lugar los procesos de convergencia en el desarrollo (catching-up). Solo a través de la clara comprensión de sus intereses y necesidades cambiantes, así como de las ventajas y activos propios, es posible identificar oportunidades para construir un camino que conduzca al desarrollo. Los casos de los cuatro "tigres asiáticos" y ahora de China y la India muestran cómo la pertenencia a la periferia ya no constituye una situación de "dependencia" estática, sino más bien potencialmente dinámica. ${ }^{1}$

Por supuesto, aun en las mejores condiciones, todos los procesos de adelantamiento toman tiempo, requieren persistencia y esfuerzo y exigen un aprendizaje activo para poder relacionarse con los más poderosos sobre la base de ventajas mutuas reales. Estos procesos son

\footnotetext{
${ }^{1}$ A juicio de la autora, la teoría de la dependencia fue una explicación válida de las condiciones prevalecientes durante la era de la producción en masa, especialmente durante los años cincuenta, sesenta y setenta. A partir de la revolución informática y el consiguiente proceso de globalización, el contexto cambia radicalmente y exige ser analizado de nuevo.
}

también difíciles, desiguales y muchas veces injustos, pero hasta ahora no se han encontrado atajos (Bell, 2006; Pérez, 2001, pp. 126-128).

Aunque la argumentación se basa en los trabajos de la autora sobre los patrones recurrentes en la difusión de las revoluciones tecnológicas, este breve artículo no permite resumir esos patrones o pasar revista al significado de los conceptos y la terminología. Se espera que, para los propósitos actuales, sean suficientes las explicaciones sucintas proporcionadas en el texto. ${ }^{2}$ Más aún, se recomienda al lector considerar este escrito como un ensayo más que como un artículo de investigación, como una propuesta sustentada en una particular visión del mundo más que como un análisis empírico del contexto o de la viabilidad. Está destinado a abrir, más que a clausurar, un debate necesario.

En la siguiente sección se examina la globalización como un elemento intrínseco al paradigma de las TIC y se particularizan tres procesos de hipersegmentación con fuerte influencia en la definición del espacio de oportunidades. Luego se presentan los grandes rasgos del modelo dual, identificando las direcciones generales de la especialización de las industrias de procesos basadas en recursos naturales, teniendo en cuenta tanto la urgente necesidad de combatir la pobreza como el auge asiático. En las siguientes tres secciones se analizan en detalle las tres hipersegmentaciones clave — de los mercados, las cadenas de valor y las tecnologías-, considerando cómo cada una de ellas define espacios de oportunidad en las dos direcciones de la estrategia propuesta. En la siguiente sección se muestra cómo la especialización basada en los recursos naturales puede también preparar el terreno de manera efectiva para la inserción exitosa en lo que parece ser la próxima revolución tecnológica (probablemente basada en las ciencias de la vida y de materiales). Luego se discuten brevemente las teorías acerca del desarrollo basado en los recursos naturales y se indica por qué se puede considerar que las condiciones actuales crean una ventana de oportunidad para emprender esa ruta de desarrollo. En la sección final se sostiene la necesidad de revitalizar el papel del gobierno como constructor de consensos y facilitador proactivo de la estrategia en sus dos componentes.

\footnotetext{
${ }^{2}$ Los lectores interesados pueden visitar la página web de la autora www. carlotaperez.org, así como las publicaciones citadas en el texto.
} 


\section{II \\ La globalización y sus determinantes EI paradigma de las TIC y la corporación global}

Cada revolución tecnológica ofrece un enorme potencial de generación de riqueza y bienestar social. Cada una es claramente superior a las anteriores en términos de efectividad y productividad, no solo por las nuevas tecnologías, sino también por el nuevo "paradigma tecnoeconómico y organizativo" que las acompaña como óptima práctica. En cada oleada sucesiva se articula un conjunto de principios, métodos, formas organizacionales y criterios nuevos y distintos. Los emprendedores, las empresas, los gobiernos y las sociedades se benefician en mayor o menor medida de ese potencial según su capacidad para adoptar el nuevo paradigma y adaptarlo a sus propósitos específicos.

Muchas de las prácticas del paradigma de las TIC están siendo incorporadas de manera gradual y general hasta ser aceptadas como obvio "sentido común" organizativo. Las redes descentralizadas con un centro coordinador reemplazan a las pirámides cerradas, centralizadas y rígidamente controladas. La mejora continua y la innovación están reemplazando a la práctica anterior de rutinas estables y cambio planificado. Nociones como la de "capital humano" y el poder creador de valor del conocimiento y la experiencia están desplazando a la visión del personal como "recurso humano". Aunque todavía hay resistencia ante algunos de estos cambios, ningún otro ha estado tan sujeto a debate y a posturas extremas como el proceso de globalización.

La globalización es un rasgo intrínseco del paradigma de las TIC, no así la liberalización total (Pérez, 2009). Las características de las TIC hacen permeables las fronteras nacionales y amplían la escala potencial de producción, facilitando y requiriendo mercados a nivel planetario. Pero las políticas de "libre mercado", en el sentido de permitir al mercado actuar por su cuenta - desregulado, sin guía ni restricciones nacionales o globales-, dejaron ya de ser efectivas.

La globalización no supone la desaparición del Estado-nación o de los gobiernos nacionales, aunque es probable que estos eventualmente deleguen algunos poderes a instituciones supranacionales y otros a gobiernos locales. Con la globalización se aprovecha al máximo la diferenciación regional, nacional y local, tanto en la producción como en los mercados. Quizás en el lema de los ambientalistas "pensar globalmente, actuar localmente" es donde mejor se recoge el significado del proceso globalizador. Los gobiernos nacionales tienen un papel crucial en el condicionamiento que definirá el papel a jugar por cada país en la globalización. ${ }^{3}$

La identificación de posibles ventanas de oportunidad no solo requiere comprender la naturaleza del paradigma de las TIC, sino también la naturaleza de las nuevas corporaciones globales. Ellas son los verdaderos agentes de la globalización y sus intereses son la clave para el diseño de estrategias de suma-positiva.

Hay una profunda diferencia entre las viejas empresas multinacionales y las corporaciones globales (CG) actuales. Las primeras fueron resultado de la fase final del paradigma de la producción en masa y una manera de manejar la madurez y la saturación de los mercados; las CG actuales son organizaciones capaces de aprovechar el nuevo paradigma de las TIC para obtener las máximas ventajas.

El nombre de la corporación global moderna la explica por sí mismo. Ahora no se trata de una casa matriz con filiales en múltiples mercados, ni tampoco solo de aprovechar los bajos costos de producción de los diversos países; se trata de una estructura diferente con una lógica distinta. Es la forma óptima de la nueva organización en redes establecida a lo largo y ancho del planeta, dirigida y facilitada por la revolución de la información y las comunicaciones. Esto afecta profundamente a la empresa misma.

La penetración de los mercados globales es consecuencia directa de la aplicación y el aprovechamiento de todas las ventajas del potencial y las características de las TIC. Ahora es posible alcanzar niveles más altos de productividad con organizaciones en red que abarcan el globo. La infraestructura de la Internet, con sus satélites y cables de fibra óptica transoceánicos, hace posibles las comunicaciones fluidas e instantáneas a todo lo ancho y largo del mundo y permite evaluar al planeta entero en términos de ventajas comparativas. De ese modo, se

\footnotetext{
${ }^{3}$ Si hay un caso en el mundo en que el Estado mantiene el control de la inversión extranjera utilizando todo tipo de límites, restricciones, regulaciones y negociaciones es el de la China actual. No solamente negocia con firmeza sus mercados y sus ventajas de bajo costo, sino que define la parte del territorio y los sectores en que han de operar las empresas extranjeras, y establece las condiciones para la participación y el aprendizaje locales. Este fue también el caso de la República de Corea y de muchos otros países exitosos.
} 
pueden valorar las condiciones para la "tercerización" (outsourcing), la exportación del trabajo (off-shoring), las alianzas estratégicas y otras opciones, la estimación de las cualidades y costos de la ingeniería, la producción, el transporte y las transacciones "como si" el espacio económico fuese abierto y sin fronteras, pero tomando muy en cuenta las condiciones y políticas de cada país.

Las capacidades de coordinación proporcionadas por las TIC hacen posible alcanzar niveles de complejidad organizacional y de tamaño que trascienden el máximo alcanzable por las antiguas multinacionales, o por las corporaciones transnacionales con estructuras piramidales y lentos sistemas de información. Ahora no solo es posible orientar, hacer seguimiento y controlar una organización verdaderamente gigantesca, sino que también la cobertura territorial y la complejidad estructural son relativamente fáciles de manejar con las TIC y pueden serlo todavía mucho más con innovaciones adaptativas mayores.

El proceso de globalización ha traído consigo la hipersegmentación de tres áreas clave: las cadenas de valor, los mercados globales y las competencias tecnológicas. Cada una de estas áreas se convierte en una red compleja con componentes diferenciados. El resultado se puede caracterizar como una "descentralización integrada" o una "componentización sistémica", donde cada componente tiene un nivel muy alto de autonomía dentro de una estructura interfuncional e interactiva.

En la estructura de cada corporación la red de valor se segmenta (incluidos los proveedores y clientes) en componentes y subcomponentes capaces de conectarse mediante diversos tipos de relación, desde su integración en la estructura central, pasando por la condición de contratista estable independiente o aliado, hasta la de proveedor temporal a quien se recurre solo cuando surge la necesidad. A su vez, cada uno de estos componentes se apoya en su propia red de relaciones sobre la base de un alto grado de autonomía, lo que en estas estructuras se considera indispensable para asegurar la flexibilidad y la competitividad. Los componentes pueden estar territorialmente disgregados en varios países y aun así conformar una sola "red de valor global" apalancada y coordinada por la corporación global. ${ }^{4}$

Esta capacidad para manejar redes complejas facilita también la hipersegmentación de los mercados, favoreciendo un perfil de productos altamente diversificados y de gran adaptabilidad a una amplia gama de demandas específicas e incluso ultraespecializadas.

Cuando la red de valor se ha segmentado hasta llegar a los subcomponentes más simples y los mercados se han fragmentado en innumerables nichos, las capacidades tecnológicas se pueden singularizar y la especialización innovativa profunda permite que unidades o empresas intensivas en conocimiento prosperen dentro o fuera de la corporación global. En el otro extremo, algunos métodos artesanales tradicionales pueden también ocupar nichos de alto valor (premium).

Estas características del proceso de globalización abren ventanas de oportunidad específicas para las empresas y países de América Latina. Esas oportunidades serán analizadas luego de describir la estrategia general propuesta y en relación con ella.

\footnotetext{
${ }^{4}$ En http://www.globalvaluechains.org el lector encontrará abundante literatura en línea sobre las cadenas de valor globales vistas desde la óptica de los países en desarrollo.
} 


\section{III \\ El contexto global y las ventajas de poseer recursos naturales Una estrategia dual para una realidad dual}

Existen dos realidades que enfrentar cualquiera sea la estrategia de desarrollo de América Latina. Una es la naturaleza de la competencia con China y otros países asiáticos en los mercados globales. La otra es la profunda polarización de la distribución del ingreso y la proporción inaceptable de la población latinoamericana sometida a la pobreza.

La dirección tomada por el actual proceso de globalización parece haber dado a Asia el rol de "fábrica del mundo" en lo concerniente a las "industrias de fabricación" (electrónica, aparatos eléctricos, ropa, y otros rubros). Las ventajas sobre las cuales se organiza esta especialización global son las inmensas cantidades de fuerza de trabajo barata y el abundante número de ingenieros y de personal altamente educado en su población. La escasez de materias primas en ese continente, en relación con sus necesidades de crecimiento, ha permitido que América Latina y África exporten crecientes cantidades de minerales, energía y productos agrícolas a precios cada vez más elevados.

América Latina tiene cada vez más dificultades para competir en la fabricación, especialmente en las áreas de productos de alto volumen y bajo costo. Su densidad poblacional es muy inferior a la de Asia y la mano de obra, a pesar de ser muy barata, sobrepasa con mucho el nivel asiático de salarios. Sin embargo, su rica dotación en recursos naturales y energía le ofrece una ventana de oportunidad para especializarse en "industrias de procesos". ${ }^{5}$ El problema tradicional de la monoexportación de materias primas podría transformarse en un futuro exitoso de tecnologías complejas, variado perfil exportador y elevado crecimiento si se aprovecharan

\footnotetext{
5 El concepto "industria de fabricación" se usa para referirse a la manufactura de productos mediante el ensamblaje de partes diferentes (automóviles, equipos mecánicos, eléctricos y electrónicos, ropa, y otros) generalmente en talleres y línea de ensamblaje usando mano de obra. El concepto "industria de procesos" se refiere a la transformación directa de materias primas mediante métodos químicos, eléctricos, calor u otros (acero, papel, salsa de tomate, gasolina, plásticos), y servicios como las telecomunicaciones. La diferencia principal reside en que el proceso de producción tiene lugar "dentro" del sistema de equipamiento y el personal supervisa y apoya el proceso en lugar de ejecutarlo. Véase Woodward (1965).
}

de manera inteligente las ventajas de poseer recursos naturales.

Además, es de esperar que el proceso globalizador tienda a elevar el nivel de precios de los recursos naturales en general (aunque sin eliminar la volatilidad). La perspectiva de un nivel promedio favorable en los precios de estos productos abre un posible camino para financiar el esfuerzo tecnológico y de formación de capital humano vinculado a tales productos. La región podría convertirse en el proveedor de insumos materiales, comida y otros bienes agrícolas (desde los más estándar hasta los productos a la medida más sofisticados) para el resto del mundo.

La estrategia implicaría el escalamiento tecnológico constante de las actividades basadas en recursos naturales y la mejora gradual del perfil de las exportaciones mediante innovaciones continuas en productos, procesos y actividades auxiliares, sobre todo con la visión de crear nichos de alto valor diferenciándolos de los tradicionales mercados de productos básicos (commodities). Esto supone la transformación gradual de toda la economía. La idea sería comprometerse en un esfuerzo concentrado por dominar las tecnologías de las industrias de procesos, desde los commodities en gran escala (acero, aluminio, papel, refinación, cerveza, petroquímica y ciertos alimentos), pasando por las especialidades de escala intermedia (química, biotecnología, nanotecnología), hasta los materiales en pequeña escala hechos a la medida y los químicos especiales u otros productos de nicho. Este esfuerzo puede echar sus raíces en las capacidades adquiridas por cada país en su área específica de dotación de recursos naturales, así como en otras industrias procesadoras - metalurgia, química, procesamiento de alimentos-, y podría avanzar a lo largo de las nuevas trayectorias tecnológicas abiertas por la ciencia de los materiales y las ciencias de la vida. Los objetivos serían la migración gradual hacia productos con un valor agregado cada vez mayor, con características cada vez más especializadas y adaptadas al cliente, y el establecimiento de potentes redes de innovación (con participación de empresas y universidades locales, continentales e internacionales) haciendo que el esfuerzo sea sostenible en el tiempo. En la figura 1 se representa la idea mediante un diagrama. 


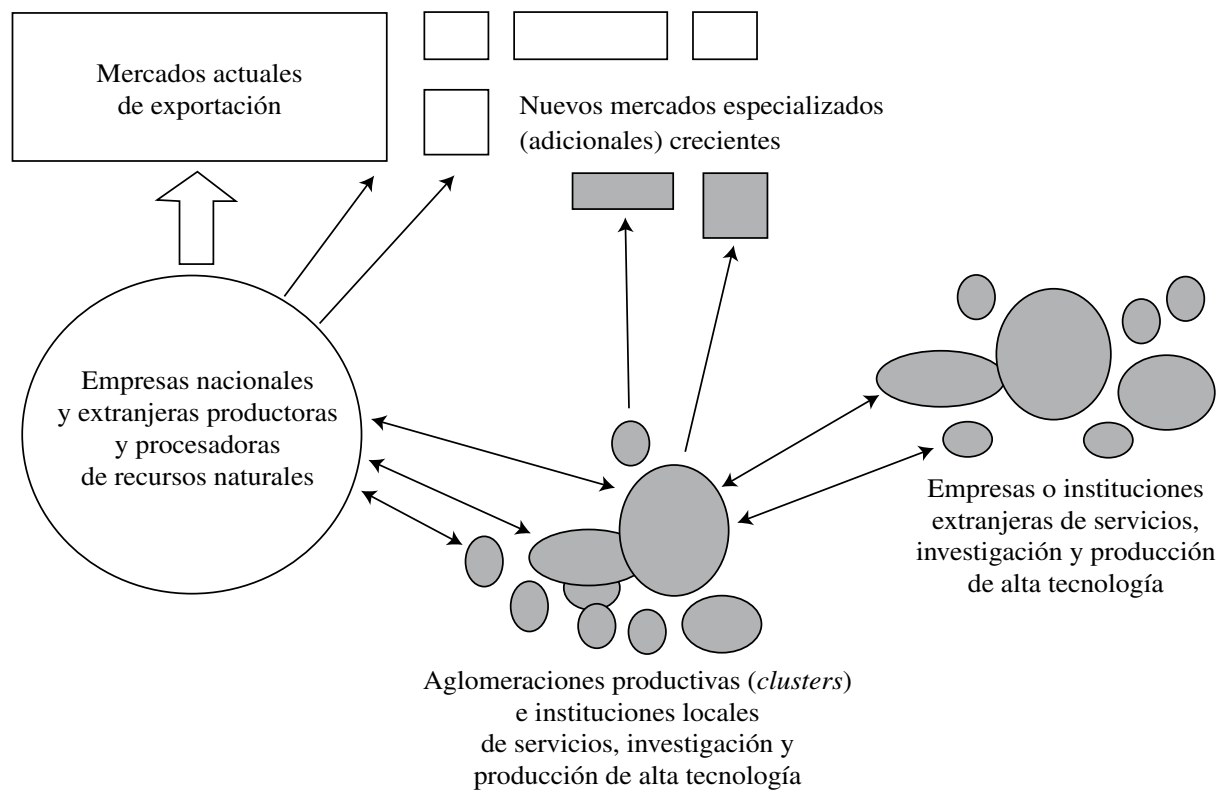

Fuente: elaboración propia.

Algunas redes de innovación podrían ser creadas con la participación activa de las CG extractivas o agrícolas, sean extranjeras o nacionales. O podrían construirse mediante la asociación de empresas locales en aglomeraciones formales e informales (como los productores de vino, de flores, de cacao, los cultivadores de productos orgánicos, las posadas y guías turísticas, los diseñadores de textiles, entre otros).

La idea sería fortalecer los conocimientos técnicos (know-how) acumulados por cada país en sus productos de exportación actuales para entonces desplazarse tecnológicamente aguas arriba, aguas abajo y lateralmente a lo largo y ancho de las redes de valor relevantes. ${ }^{6}$ Los esfuerzos se dirigirían a un conjunto de objetivos específicos definidos según la dotación de recursos naturales y la acumulación de capacidades previamente lograda por cada país. Entre estos se pueden encontrar los siguientes:

\footnotetext{
${ }^{6}$ En su argumentación en relación con la posibilidad de una estrategia para África basada en los recursos naturales, Walker y Jourdan (2003) insisten en la importancia de lo que denominan innovaciones laterales, es decir, aquellas cuyo origen tuvo lugar, por ejemplo, en la minería, pero que por su naturaleza genérica pueden luego ser utilizadas en otras industrias.
}

- Dar calidades especiales a los materiales de exportación actuales para apuntar a mercados de nicho, como por ejemplo, madera antitermitas (o elástica), materiales adaptados al cliente o biodegradables, o aleaciones y compuestos especiales.

- Desarrollar mayores capacidades en cuanto a productos adaptados al cliente o nichos en las grandes industrias procesadoras (metalurgia, petroquímica, papel, vidrio, y otros).

- Aumentar las capacidades tecnológicas de las industrias de bebidas y procesamiento de alimentos (en relación con las tecnologías de productos y de procesos).

- Incrementar las capacidades tecnológicas de las industrias relacionadas con la agricultura de exportación, productos animales, pesca, silvicultura, y otras, y desarrollar aun más las industrias productoras de insumos para ellas.

- Rescatar los innumerables vegetales y frutas autóctonas - con su agradable sabor y textura- y desarrollar las tecnologías necesarias para que lleguen en perfecto estado a mercados de nicho gourmet con altos precios.

- Definir áreas destinadas a productos "orgánicos" y establecer un sistema de otorgamiento de certificados de origen. 
- Desarrollar la biotecnología orientada a la salud para la identificación de necesidades locales humanas, animales o vegetales, y para la mejora de las exportaciones relacionadas con ellas.

- Promover las capacidades en materia de protección ambiental mediante energías alternativas, reciclaje, captura de contaminantes, entre otros.

- Explotar los diversos tipos de turismo moderno, aprovechando todas las ventajas de la variedad de condiciones naturales e históricas existentes y utilizando modelos de negocio imaginativos.

- Alcanzar capacidad de diseño a la medida en aditivos, catalizadores y otros químicos especializados que puedan requerir las industrias de procesos (locales o globales).

- Impulsar una industria especializada de bienes de capital capaz de responder a las especificaciones sencillas o sofisticadas de las industrias de procesos (grandes, medianas o pequeñas).

- Desarrollar o fortalecer industrias complementarias de programas, sistemas y otros servicios de computación (software) e instrumentos electrónicos igualmente capaces de responder a especificaciones de los usuarios.

- Promover una densa red de empresas pequeñas intensivas en conocimiento (EPIC) para servir a cada una de las áreas de especialización.

- Intensificar las direcciones correspondientes en cuanto a investigación y desarrollo (I+D) y educación.

La dotación específica de recursos naturales y los niveles de conocimiento y experticia adquiridos por cada país señalarían las áreas preferenciales de especialización a seguir, así como los vínculos y alianzas que convenga establecer dentro y fuera de la región. Los nuevos conocimientos y la experticia requeridos para proseguir por los caminos sugeridos supondrían necesariamente el establecimiento de redes y alianzas globales, tanto con la comunidad académica y de investigación como con las corporaciones globales que lideran las industrias en cuestión. Es probable que también se requiera inversión extranjera y el establecimiento de alianzas estratégicas e inversiones conjuntas entre las CG y las empresas locales, así como entre empresas de la región.

Al evaluar el potencial para emprender una estrategia como la propuesta, conviene empezar por reconocer la gran diversidad de herencias tecnológicas en los países latinoamericanos. No obstante, hay rasgos comunes en la historia de la región que permiten realizar una evaluación gruesa y estilizada que abarque al conjunto de países a grandes rasgos:
- Mientras las plantas ensambladoras establecidas bajo el modelo de sustitución de importaciones restringían la innovación (muchas veces por obligación contractual), las actividades de exportación —con frecuencia en manos de las multinacionales- estaban actualizadas en lo tecnológico, empleaban personal local para las actividades gerenciales y técnicas, y solían practicar la innovación adaptativa. ${ }^{7}$

- Las industrias complementarias desarrolladas para suplir a las plantas de ensamblaje (como las de vidrio, papel, cartón, plásticos, empaquetado, artes gráficas, cemento, pintura, cerámica, y otras) y las básicas agroindustriales (de cerveza, leche, jugos, café, pasta, y otros) son fundamentalmente industrias de procesos que utilizan materia prima local y, por ello, requirieron adaptaciones y mejoras, aun cuando estuviesen basadas en tecnologías y equipos extranjeros. ${ }^{8}$

- La mayor parte de las redes de infraestructura de servicios, generalmente establecidas por los gobiernos, como los teléfonos, la electricidad, los sistemas de agua y desagüe, eran manejadas por personal local, para lo cual era necesario tener capacidad operacional y de mantenimiento, así como habilidad para realizar pequeñas mejoras y adaptaciones. Una vez privatizadas, las empresas extranjeras trajeron nuevas tecnologías y actualizaron al personal local tomando como base su experiencia previa.

- En algunos países el avance "aguas arriba" de la sustitución de importaciones orientado a la industria del acero, la petroquímica o los bienes de capital, se realizó con la acumulación resultante de experiencia tecnológica (know-how) y capacidades de ingeniería, así como de cierta capacidad de innovación.

- Más tarde, con la apertura de las economías y la llegada de la revolución informática, en la mayoría de los países se desarrollaron empresas locales para diseñar productos de hardware y software y para ofrecer integración de sistemas, mantenimiento y otros servicios.

En conjunto, esto indica que la historia común de los esfuerzos de industrialización en América Latina ha dejado como legado una cierta inclinación a las industrias de procesamiento y suficientes capacidades de

\footnotetext{
${ }^{7}$ Dada la especificidad local de la producción de materias primas (o de su extracción), algunas innovaciones importantes se hicieron in situ. En el Lago de Maracaibo, en Venezuela, tuvieron lugar innovaciones pioneras en perforación subacuática.

${ }^{8}$ Véanse, por ejemplo, Vera-Cruz (2006) y Dutrénit (2006) para la fabricación de cerveza y botellas en México.
} 
TIC como plataforma mínima de experticia tecnológica para esta estrategia. Sin embargo, la propuesta descansa en un gigantesco esfuerzo en educación, capacitación y aumento de la capacidad tecnológica a todo lo largo del espectro aludido.

Desafortunadamente, exceptuando el turismo y algunos sectores agrícolas, la mayoría de las industrias de procesos no son intensivas en mano de obra, sino más bien en capital y capacidades. Más aún, la reorientación propuesta las haría incluso más intensivas en conocimiento. Por lo tanto, la estrategia demanda un esfuerzo complementario para promover algunas industrias de alto empleo (construcción, salud, servicios personales). Pero eso no sería suficiente.

Los temas relativos a la distribución del ingreso y la pobreza están en la palestra debido a la polarización social experimentada por los países emergentes exitosos como China y la India. Es bien sabido que América Latina ha presentado tradicionalmente una distribución muy polarizada del ingreso, así como una marginación social en el campo y en las barriadas alrededor de las principales ciudades. Estos rasgos empeoraron durante la "década perdida" generando descontento social, resentimiento y vivos deseos de cambio. Cualquier estrategia de crecimiento que no reconociera esta cruda realidad sería socialmente inaceptable y políticamente inestable.

El objetivo del desarrollo debe ser el promovido por Fernando Fajnzylber en la CEPAL en 1990, en la publicación Transformación Productiva con Equidad. ${ }^{9}$ Este autor ya había señalado que el crecimiento en Asia y el sur de Europa durante los años setenta había reducido las inequidades, mientras la mayoría de los países latinoamericanos habían crecido con gran desigualdad en la distribución del ingreso. ${ }^{10}$ Es interesante notar que, durante su proceso de convergencia en el desarrollo (catching-up), los cuatro "tigres asiáticos" establecieron

\footnotetext{
${ }^{9}$ CEPAL (1990). Véase también CEPAL (2008).

${ }^{10}$ Fajnzylber (1990), gráfico 1, p. 12. El tema se mantiene en la agenda cepalina, con especial referencia a la heterogeneidad estructural como fuente de la magnitud y persistencia de la desigualdad. Al respecto, véase, por ejemplo, Infante y Sunkel (2009).
}

programas educativos universales masivos con una fuerte orientación técnica y desarrollaron progresivamente una distribución del ingreso más equitativa. Ambas prácticas siguen vigentes luego de los logros en crecimiento y desarrollo. ${ }^{11}$

A lo largo del análisis se sostendrá que el logro del doble objetivo de elevar la base de la pirámide junto con el crecimiento en la vanguardia de la economía se ha hecho viable, precisamente en virtud de las oportunidades que brinda el actual paradigma.

Para ello hace falta el establecimiento de una estrategia dual o un "modelo dual integrado". Por una parte, estaría la consecución del dominio tecnológico (la especialización profunda) en las industrias basadas en recursos naturales hasta alcanzar posiciones sólidas en los espacios del mercado global; por otra, el desarrollo de la capacidad de creación de riqueza en cada rincón del territorio para mejorar la calidad de vida de sus habitantes, apalancando las ventajas locales y apuntando a nichos de mercado (globales, nacionales o locales). En la primera parte de la estrategia el objetivo es la competitividad; en la segunda, la competitividad se convierte en un medio para lograr el bienestar de la población involucrada. La primera se orienta al crecimiento "desde arriba"; la segunda al crecimiento "desde abajo". Los sectores impulsados en la primera serían los motores del crecimiento de la economía; los desarrollados en la segunda serían abordados como medios para salir de la pobreza.

En la última sección se afirmará que las dos vertientes del modelo dual deben ser aceptadas por la sociedad e integradas ideológicamente, pero que su promoción requerirá instituciones separadas. Se discuten a continuación cómo las tres hipersegmentaciones características del proceso globalizador abren oportunidades en ambas mitades de esta estrategia dual.

\footnotetext{
${ }^{11}$ La República de Corea, Singapur y la Región Administrativa Especial de Hong Kong están entre los 28 primeros países (con resultados mayores de 0,9) en el índice de desarrollo humano (PNUD, 2007).
} 


\section{IV \\ La hipersegmentación de los mercados Oportunidades en ambas mitades del modelo dual}

La revolución de las TIC ha traído consigo la infinita fragmentación de todos los mercados, no solamente en la manufactura, sino también en las materias primas y en los servicios, por lo que la noción de producto básico (commodity) se aplica ahora a muchas manufacturas, desde los teléfonos celulares y las computadoras de mesa hasta las franelas y los refrigeradores, mientras que la idea de nicho de "especialidad" se relaciona ahora frecuentemente con segmentos de materias primas como ciertos tipos premium de café o de aceros especiales.

En cada caso, el segmento de los commodities es simplemente la versión del producto en volúmenes muy elevados del modelo más sencillo y de bajo costo, una vez que ha alcanzado cierto grado de madurez. El margen de beneficio de los commodities industriales es muy exiguo y la producción con ventajas comparativas es absolutamente indispensable para alcanzar el éxito. Por otra parte, muchos mercados de materias primas tienen capas superiores cuyas calidades especiales les confieren un valor adicional en el mercado, llegando en algunos casos a convertirse en semimonopolios de precios elevados y relativamente estables (Kaplinsky, 2005). Lo mismo puede decirse, naturalmente, de los servicios y productos industriales hechos a la medida, los de marca o los organizados en modelos de negocio creativos. En la figura 2 se presenta un mapa de la segmentación de los mercados, indicándose las dos direcciones principales de la diferenciación, la proporción relativa de los márgenes de beneficio en cada una y cómo estos se obtienen y protegen. En la figura 3 se ofrecen algunos ejemplos ilustrativos y se indican las direcciones a seguir para mejorar el posicionamiento en el mercado.

Una de las consecuencias de esta compleja estructura de los mercados es tener que pasar de considerar a la "industrialización" como cima del desarrollo a la necesidad de acuñar un término como "tecnologización” para referirse a las posiciones más ventajosas en los mapas globales del mercado (por ejemplo, el movimiento desde los productos o servicios "básicos" hacia las posiciones angulares del esquema, relativas a lo "especial", lo "único" o "a la medida" como se aprecia en la figura 3). Esto, junto con el aumento del precio de las materias primas provocado por el avance de la globalización, puede contribuir a eliminar o disminuir de manera significativa la desventaja tradicional de las materias primas.

Otra consecuencia de esta estructura caleidoscópica es la abundancia de espacios para la coexistencia de las PYME con corporaciones gigantes, y para que los productos tradicionales puedan aspirar a incorporarse al mercado mundial junto con los de alta tecnología. Por lo anterior, apostar al mercado adecuado no es solo un prerrequisito, sino también una rica posibilidad tanto para los sectores que crecen "desde abajo" como para los que crecen "desde arriba".

Más aún, debido a esta hipersegmentación la forma usual de agrupar sectores industriales en la época de la producción en masa se hace inadecuada. En lugar de clasificar por tipo de producto o proceso de producción, la agrupación sectorial de industrias se hace ahora con frecuencia en función de los mercados de destino. Un empresario de telas producidas y tratadas para la confección de velas para barcos ya no pertenece a la industria textil, sino a la de los deportes y el ocio. Una empresa especializada en zapatos para diabéticos se clasificaría entre las industrias de la salud y así sucesivamente. Las industrias de los deportes y el ocio, el entretenimiento, la protección ambiental, la salud y las industrias creativas se reconocen como categorías cada vez más relevantes. Típicamente, estas nuevas industrias ofrecen oportunidades más lucrativas y protegidas para los productores especializados, así como canales de distribución especiales.

Un aspecto particularmente útil de la diversidad de los mercados es la apertura de oportunidades para producir a mucho menor escala. En tiempos del paradigma de la producción en masa, la producción debía ser de varios contenedores o de varias toneladas mensuales para considerar siquiera la posibilidad de exportar. Ni los sistemas de transporte ni los de distribución estaban orientados al manejo de pequeñas cantidades de producto alguno. Hoy día existen innumerables tiendas especializadas en productos de "nichos" globales; los supermercados y las tiendas de departamentos incorporan a su negocio la oferta de una 
FIGURA 2 La hipersegmentación de los mercados bajo el paradigma
de las tecnologías de la información y las comunicaciones

Alta rentabilidad debido a cualidades especiales. Mercados protegidos por diferenciación, innovación, tecnología, marcas y patentes

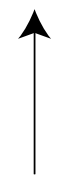

Rentabilidad alcanzada mediante alto volumen.

Mercados protegidos por bajo costo, producto básico y entrega confiable

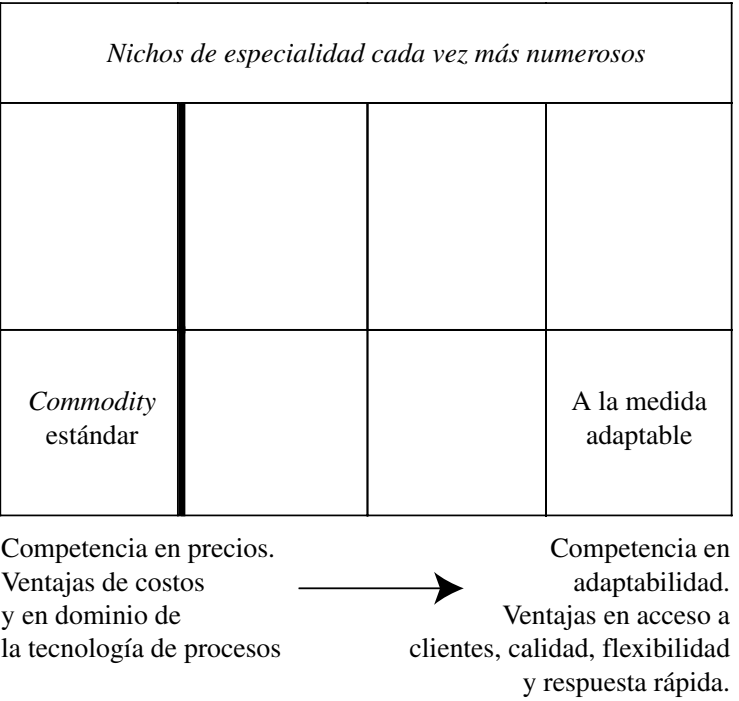

Fuente: elaboración propia.

FIGURA 3

Ejemplos de posicionamiento

Alimentos orgánicos Aceros "boutique". Combustibles limpios.

Café Starbucks.

Lona para barcos a vela. Calzado para diabéticos.

Frutas "gourmet"

Madera antitermitas.

Bacterias para

digerir derrames

Turismo de aventura.

Trigo; carne

Partes automotrices. Software estándar.

Discos duros.

Teléfonos celulares.

Torres desktop

Turismo de playa.

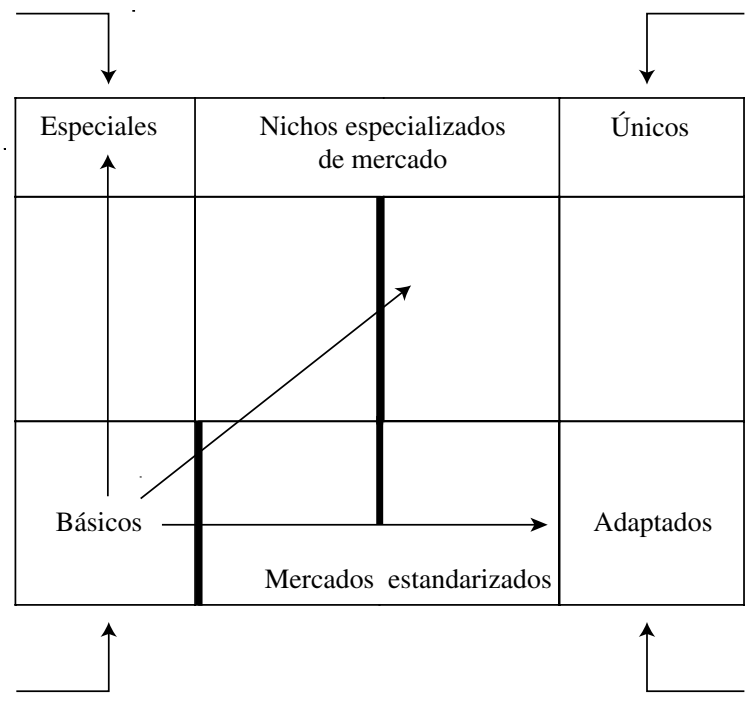

Diseño de aeropuertos o edificios emblemáticos. Grandes sistemas de información.

Servicios de I+D o instrumentos especiales Viagra (al inicio).

Turismo en Chichén Itzá o en el Amazonas.

Computadores Dell. Software de e-gobierno. Ensalada en bolsas a pedido a distancia. Servicios personales. Soporte técnico. Turismo de salud: Operaciones de cadera.

Fuente: elaboración propia. 
amplia variedad de especialidades; a su vez, el servicio global de encomiendas (courier) ha desarrollado sistemas muy eficientes de transporte y entrega de cualquier cosa con cualquier frecuencia a precios relativamente decrecientes. La innovación en esta dirección ya comenzó y está teniendo una demanda en aumento.

En este nuevo mundo donde proliferan los nichos de mercado, la gama de productos es extremadamente amplia y va desde los más tradicionales hasta los de tecnologías más complejas e intensivas en conocimiento. Hay nichos para la cerámica artesanal y para equipos de diagnóstico biotecnológico. Los servicios de larga distancia van desde los centros de llamadas hasta la interpretación de datos geológicos; los servicios locales "tercerizados" comprenden desde la preparación de comidas hasta la protección de datos; las exportaciones especializadas incluyen desde excelentes mermeladas o quesos locales hasta servicios de detección de fallas en sofisticados equipos de procesos; las ofertas turísticas incorporan desde una aldea en los Andes organizada como una "experiencia local" o una excursión de observación de aves en la selva tropical, hasta una conferencia en un centro de tecnologías complejas ubicado en un hermoso paraje; las actividades de protección ambiental ofrecen desde productos "orgánicos" certificados hasta el uso de bacterias especialmente desarrolladas para "digerir" derrames petroleros. La variedad es tan amplia como la diversidad de condiciones locales; los límites los pone la imaginación emprendedora.

Otra noción valiosa para identificar las nuevas oportunidades es la de "glocalización". Esta se refiere tanto a la adaptación de productos globales a las condiciones locales como a la identificación de productos locales con potencial global.

\section{V \\ La hipersegmentación de las redes de valor Estrategias y políticas para aprovechar las ventajas mutuas}

Existen muchos tipos de redes de valor, desde las coordinadas por una corporación global productora (como IBM, Toyota, Telefónica o Zara), pasando por las redes de proveedores de las CG puramente comerciales -controladas por empresas distribuidoras (buyer-driven) como Walmart o TESCO - hasta los distritos industriales formados localmente para vender globalmente. ${ }^{12}$ Lo que tienen en común es la combinación de la autonomía de cada elemento con el poder de coordinación sobre toda la red. En el caso de las CG, el centro define los objetivos y los grados de autonomía de los elementos; en el caso de las asociaciones de productores independientes, son los elementos los que definen la estrategia y las atribuciones del núcleo común. Estos últimos a veces llegan a formar parte de la red de una CG.

Es importante notar que en estas estructuras el grado de competitividad se define más a nivel de la red que al de cualquiera de sus componentes. En consecuencia, las relaciones dentro de la red serán evaluadas según la contribución de cada componente al conjunto.

\footnotetext{
${ }^{12}$ En relación con las redes impulsadas por productores o compradores (producer o buyer-driven), véanse Gereffi (1994) y Gereffi y Kaplinsky (2001). Con respecto a las redes locales, véase Schmitz (2004).
}

El vínculo entre esta contribución y la distribución relativa de los beneficios a lo largo de la red está, por supuesto, marcadamente mediado por el poder relativo y la información sobre la red y los mercados poseída por cada participante (Schmitz, 2004).

Las empresas aisladas no lo pasan bien en el paradigma de las TIC. Las relaciones a distancia con proveedores, clientes y competidores, características del paradigma de producción en masa, dejaron de dar buenos resultados y hasta pueden amenazar la supervivencia. Este hecho está en la base del éxito de las estrategias de formación de aglomeraciones productivas (clusters) y de franquicias en el mundo entero, así como también de los programas de los gobiernos y las agencias internacionales para promover diversas formas de asociación destinadas a compartir costos, o realizar conjuntamente las actividades de entrenamiento o mercadeo global. Ello también explica la formación de clusters estables o consorcios para ayudar a sobrevivir a industrias ya establecidas o generar nuevas actividades productivas en áreas empobrecidas. Igualmente subyace a los intentos de muchas empresas en América Latina por convertirse en proveedoras de CG comerciales o productivas, con diferentes niveles de éxito. 
Con esta discusión sobre la segmentación de los mercados se pretende dejar en claro que mientras más cerca se encuentre un producto o servicio de la esquina de los commodities del mapa de los mercados, mayores serán la presión de los precios y la exigencia de una calidad estándar estable y básica con mínimas desviaciones respecto de las especificaciones y los tiempos de entrega. Cuanto más especial sea el producto o servicio o incorpore mayor valor de conocimiento, tanto mayor será el poder de negociación del proveedor.

Es cierto que en algunos países de la región se disfruta de ciertas capacidades o tradiciones únicas, capaces de representar una especialidad valiosa, o de algunos especialistas o innovadores altamente reconocidos en condiciones de exigir un valor adicional (premium) por su trabajo. Pero es probable que la mayoría deba comenzar el proceso de aprendizaje desde la base para luego intentar reposicionarse innovando "hacia arriba" y lateralmente para apuntar a productos o servicios de nicho. Ello sugiere la conveniencia y necesidad de diseñar y establecer los mecanismos de apoyo adecuados, especialmente para la mitad "desde abajo" de la estrategia.

Pero quizás la discusión sobre las condiciones para incorporarse a redes es más relevante para la mitad de la estrategia "desde arriba" relativa a los motores del crecimiento, que en última instancia es la que financia a la otra mitad. En la literatura sobre gerencia se ha estudiado ampliamente el comportamiento de las CG, analizando cómo sus estructuras están cambiando y difundiéndose en todo el mundo, cómo toman decisiones y cómo compiten; y en la literatura sobre el desarrollo se ha venido examinando cómo les va a las empresas y regiones que efectúan el trabajo tercerizado. ${ }^{13}$ En este artículo solo se pueden tocar aquellos aspectos de particular relevancia para la propuesta en discusión.

La compleja red geográfica de una CG está formada por una enorme variedad de relaciones con las empresas y el personal de todos los países involucrados. La corporación misma se extiende por todo el globo. En el exterior no solo se ubica a los gerentes regionales, sino también a ciertos gerentes globales para aprovechar mejor ciertas ventajas locales específicas. Muchas unidades de producción están situadas geográficamente de manera de aprovechar al máximo las diversas venta-

\footnotetext{
${ }^{13}$ En la gerencia véanse, por ejemplo, Berger (2006) y Garten (2000); por parte del desarrollo véanse Gereffi y Kaplinsky (2001), Giuliani, Pietrobelli y Rabellotti (2005), Humphrey y Schmitz (2004). Para la integración de sistemas, véanse Prencipe, Davies y Hobday (2003) y Hobday, Davies y Prencipe (2006). Para la noción de redes de producción global y la tercerización no solo de la producción, sino también de la innovación, véanse Ernst (2000) y Ernst y Kim (2002).
}

jas y, cada vez más, algunas de las unidades de apoyo (staff) se han esparcido por diversos países, incluidas las secciones de los departamentos de I+D. Esto y la mayor autonomía e incentivos para innovar dados a las subsidiarias locales abren espacios para las negociaciones mutuamente beneficiosas con los gobiernos anfitriones, a fin de elevar la calidad del empleo y de las actividades desarrolladas localmente. ${ }^{14}$ En las redes de las CG hay dos tipos de trabajadores globales: el personal en el exterior (off-shore) y el personal tercerizado (out-source). Este último es el que trabaja para las empresas locales pertenecientes a la red mediante algún tipo de alianza o contrato; mientras que el primero está "adentro" de la CG y en su nómina.

El personal local de "adentro" recibe un salario igual (o algo inferior) al del personal del país de origen de la empresa, pero generalmente mayor que el normal en el país anfitrión. Puede también beneficiarse de niveles de seguridad social que despiertan lealtad y fidelidad. $\mathrm{Ni}$ siquiera las llamadas "maquilas", como en el norte de México, siguen ya el modelo de trabajo basado en rutinas mínimas de entrenamiento. Las empresas se han visto en la necesidad de involucrar a los trabajadores en el aprendizaje del control de calidad, la mejora continua y la flexibilidad. ${ }^{15}$ Más aún, el aumento de la proporción del trabajo en estas condiciones, a medida que se incrementan las nuevas inversiones extranjeras en la misma región, puede terminar marcando el ritmo de los aumentos salariales y los niveles de educación y entrenamiento esperados en la zona.

Por otra parte, mientras más unidades de una CG haya en un país o localidad particular, mayor será la demanda de servicios y las oportunidades de subcontratación en la misma localidad, dependiendo por supuesto del tipo de unidades y de las condiciones locales.

Por razones obvias, las industrias basadas en recursos naturales han tenido que ubicarse en el exterior y tienen décadas de experiencia en un cierto modo de funcionamiento. Típicamente mantienen el control de las actividades medulares y emplean personal local en la medida de lo posible en cada nivel. Cuando necesitan tercerizar un trabajo de alta tecnología tienden a recurrir a CG de servicios, las que también puede que empleen personal local. Por esta razón, la mayoría de los países latinoamericanos con energía o recursos minerales cuentan con un importante número de profesionales de alto nivel en ingeniería y gerencia con experiencia en esas industrias, capaces de asumir algunas actividades

\footnotetext{
14 Véase Marín (2007).

15 Véase Dutrénit y Vera-Cruz (2007) sobre las maquilas mexicanas.
} 
como subcontratistas. Siempre ha habido una marcada resistencia a utilizar las empresas locales, aunque esto se podría atribuir parcialmente al legado del modelo de la industrialización mediante sustitución de importaciones (III) y a la resultante actitud laxa en cuanto a productividad y dominio tecnológico (Pérez, 1996).

En las nuevas condiciones es probable que las políticas para facilitar la "componentización"16 de las redes de valor, de acuerdo con las CG presentes localmente, puedan funcionar en forma de acuerdos de suma positiva. Por otra parte, el aumento de la demanda provocado por la globalización está exigiendo más y más inversión en materias primas y generando una demanda creciente a las empresas de servicios (Gurlit, Mencarini y Montealto, 2007). Esto presionará a las compañías globales de servicios para el traslado de personal experimentado a las nuevas zonas de operación y abrirá oportunidades para empresas locales competentes.

Las nuevas relaciones de tercerización — sean en las CG de materias primas, en la fabricación aguas abajo o en las industrias de procesos- no funcionan necesariamente a distancia y con enorme presión de precios, como en el pasado. La relación con los proveedores en la red de valor varía, por supuesto, pudiendo ir desde los viejos modos de relación que presionan sobre los precios hasta la colaboración de alto nivel y calidad, a medida que el producto o servicio pasa de tener bajos requerimientos de adiestramiento a poseer mayores niveles de intensidad en conocimientos e innovación. En el extremo superior del espectro puede haber una pronunciada interacción técnica, información compartida, contratos muy bien remunerados y hasta cofinanciamiento de innovacio-

\footnotetext{
${ }^{16}$ Este término se está utilizando en lugar de "desagregación" porque el proceso es más fino, es decir, no es solo por "partes" sino que llega hasta los "componentes" de las partes.
}

nes. La idea de la estrategia al respecto sería facilitar el proceso de ascenso a posiciones altas en las redes de valor, reconociendo que llegar a esos niveles puede requerir un escalamiento gradual y que las posiciones más bajas crean más empleo y ofrecen oportunidades para la acumulación de capacidades. El objetivo final sería ampliar y enriquecer el perfil de adiestramiento, así como el de las exportaciones.

El comportamiento actual de las CG en relación con la sociedad local y el ambiente no es tan descuidado como lo fue en muchos casos en el pasado. La tendencia a la responsabilidad social corporativa, tanto en el trato con el personal como con las comunidades aledañas y respecto del ambiente, está aumentando y probablemente se seguirá extendiendo. Este cambio ha sido quizás más ostensible en aquellas industrias en que la creatividad es el factor determinante de la competitividad, por lo que la satisfacción del personal es indispensable; pero también se ha hecho importante en las industrias de bienes de consumo expuestas a la transparencia de la Internet, de la que puede depender su imagen. Sin embargo, aun en casos como la minería, donde la distancia geográfica actúa como un escudo contra la visibilidad del comportamiento y los clientes son grandes empresas en lugar de consumidores, la responsabilidad corporativa se ha traducido en aumento de la productividad y por lo tanto tiende a difundirse como la mejor práctica normal (Warhurst, 2005). Dicho esto, sigue siendo responsabilidad de las organizaciones gubernamentales tanto nacionales como locales asegurar la preservación y la mejora del ambiente natural y humano. La información sobre los estándares de prácticas responsables de negocios, establecidas por las empresas líderes en estos campos, puede modificar las expectativas y dar forma a negociaciones realistas, mutuamente beneficiosas. También la creciente competencia por las materias primas entre Asia y Occidente tenderá a fortalecer el poder de negociación de quienes las poseen. 


\section{VI \\ La hipersegmentación de las tecnologías La especialización tecnológica y su coexistencia con los métodos tradicionales}

Las dicotomías han dejado de ser útiles para entender las nuevas prácticas óptimas bajo el paradigma de las TIC. En materia tecnológica hay un movimiento combinado de “componentización" y reintegración. Cuando todos los componentes del conjunto se han diferenciado y especializado, estos vuelven a unificarse para interactuar en una red mucho más dinámica. Y el proceso es de naturaleza fractal, porque cada segmento especializado es, a su vez, componentizado en sus partes constitutivas.

En su proceso de reestructuración, la CG determina sus "competencias medulares" (core competencies), es decir, las que son el núcleo de su posición en el mercado y de su estrategia hacia el futuro. ${ }^{17}$ Es en estos aspectos medulares donde las CG concentran su propio dominio tecnológico y sus esfuerzos de innovación. Las otras actividades son finamente segmentadas y analizadas en términos de las capacidades tecnológicas requeridas y luego, según sea el caso, pasan a ser tercerizadas bajo contrato o compradas a proveedores escogidos, cuya competencia sea en ese componente. Estos, por lo tanto, desearán alcanzar el dominio tecnológico pleno en ese aspecto particular y serán capaces de innovar en él. De tal manera que, a través de la componentización, la tercerización y la construcción de esta compleja red de valor, la CG está también construyendo una estructura innovativa a todo lo largo y ancho de la gama de actividades involucradas.

En esta estructura se abren muchas oportunidades para las empresas pequeñas intensivas en conocimiento (EPIC), tanto para el suministro cara a cara como para los servicios digitalizados a distancia. De hecho, la naturaleza del proceso globalizador genera mercados para las EPIC en cada localidad, en la medida de su expansión. A su vez, la existencia de un tejido competente y confiable de servicios intensivos en conocimiento incrementa la competitividad de todos los usuarios de la localidad y sirve para atraer ulteriores inversiones nacionales y extranjeras que continuarán fortaleciendo la red de EPIC.

\footnotetext{
${ }^{17}$ Prahalad y Hamel (1990) introdujeron el concepto de competencias medulares (core competencies).
}

Hay también amplios espacios para proveedores competentes de bienes y servicios estándar o semiestándar, con dominio suficiente de los procesos tecnológicos de mejoramiento continuo de calidad y productividad.

Ninguna de estas oportunidades aparece automáticamente. Exigen persistencia, tiempo y esfuerzos dirigidos a la construcción de las capacidades requeridas para desempeñar esos roles (posiblemente comenzando por el trabajo en mercados menos exigentes), así como el desarrollo de la capacidad de negociar una posición favorable.

Por su parte, las grandes empresas exportadoras nacionales dispuestas a convertirse en grandes CG competitivas tambien tendrán que desarrollar su capacidad de componentizar y tercerizar, mientras se afianzan en el dominio de las tecnologías medulares, en su mejora y en la innovación constante.

Aunque aquí no hayan sido mencionadas con frecuencia, es importante destacar que las industrias de electrónica, software y telecomunicaciones, así como los servicios de Internet, constituyen de hecho la plataforma básica para la competitividad de las organizaciones en red y para la participación efectiva en la economía global. En el período actual, el éxito de cualquier estrategia bajo la lógica del paradigma de las TIC requiere contar con telecomunicaciones eficientes a bajo costo y disponibilidad de servicios de software y sistemas altamente competentes, así como con EPIC de mantenimiento y seguridad. Los países latinoamericanos, en su mayoría, ya han avanzado un buen trecho en este camino. Las políticas para intensificar este proceso deberían encontrar el terreno abonado para lograr acuerdos entre los participantes.

Un rasgo particular de las TIC es la naturaleza intangible de muchos de sus productos y servicios. Esto hace posible la tercerización de la mayoría de los servicios internos de oficina, incluidos los centros de llamada a cualquier parte del planeta donde un emprendedor competente y responsable ofrezca el servicio. Lo mismo se puede decir de los servicios de traducción y de interpretación de datos complejos digitalizados en cualquier campo (geología, medicina, biología, finanzas, climatología, y otros), siempre y cuando los especialistas adecuados estén disponibles. 
El otro aspecto de los productos intangibles es la posibilidad de iniciar innovaciones ambiciosas en servicios intangibles en cualquier país, para luego globalizarlas si tienen éxito. Ese fue el caso de Skype, por ejemplo, donde la pequeña Estonia ha jugado un rol importante. Las especificidades de conocimiento o de lengua también pueden generar nichos en los mercados locales o globales. En el Brasil hay decenas de sitios web equivalentes a los sitios en inglés Web 2.0, aprovechando la publicidad en lengua portuguesa, por lo que pueden llegar a las colonias del viejo imperio portugués. El mundo "hispanohablante" también se ha desarrollado en la web y todavía le queda un largo trecho por recorrer en esa dirección (incluidos en su universo de usuarios potenciales los hispanos en los Estados Unidos).

Otro rasgo útil del paradigma de las TIC es la coexistencia de una diversidad mucho mayor de tecnologías y escalas de cuanto fue posible en tiempos de la producción en masa, como consecuencia de la hipersegmentación de los mercados. Esto abre innumerables oportunidades para la mitad del crecimiento "desde abajo" de la estrategia dual. El café orgánico cultivado a la sombra, recogido a mano y tostado siguiendo métodos tradicionales y con garantía de origen, se vende en tiendas gourmet a precios muy altos (premium), mientras el café recogido mecánicamente es la variedad commodity de bajo costo a la venta en los supermercados (donde se venderá también la variedad gourmet). No hay exclusión ni marginación de una tecnología por otra, ni tampoco homologación de precios, sino más bien un proceso de diferenciación por calidades y una gama de precios capaz de reconocer esas diferencias.

Por otra parte, las TIC hacen posible la adaptación del producto al cliente llegando hasta el nivel del consumidor individual. Esta forma de "producción artesanal de alta tecnología” o, cuando se lleva a cabo en volúmenes elevados, de lo que podríamos llamar "productos masivos adaptables" (mass customization), es una de las muchas viejas dicotomías superadas por fusión en este paradigma. ${ }^{18}$

Es inmenso el espectro de oportunidades para ir en nuevas direcciones y comercializar productos en cantidades relativamente pequeñas. Ese es el camino tomado por la innovación en nuevas fuentes y sistemas de energía; esa fue la manera como las aerolíneas de bajo costo entraron en la industria y también los intentos por crear productos para la llamada "base de la pirámide" (Prahalad, 2004). Una innovación particularmente sorprendente con la que se rompe la trayectoria de la industria automotriz en las últimas décadas es el automóvil ultrasimple de 2.500 dólares desarrollado por Tata Motors en la India. Al mismo tiempo, en California están entrando en el mercado autos eléctricos ultraavanzados, extremadamente costosos, elaborados por empresas nuevas, como Tesla, en competencia con las grandes.

Ha llegado la hora de las tecnologías "adecuadas" o "apropiadas" buscadas durante tanto tiempo. Sin embargo, el concepto debía esperar por un paradigma tecnológico capaz de manejar la coexistencia de diferentes niveles de productividad y sofisticación tecnológica, sin tener que homogeneizar el precio o los mercados. Esto se ha vuelto viable en gran medida por la facilidad con que las herramientas informáticas permiten manejar el control de inventarios comerciales y otros procesos administrativos, independientemente de cuán grande sea su volumen, cuánta su variedad o cuán frecuentemente cambien en el tiempo.

\footnotetext{
${ }^{18}$ Hemos sido testigos de la proliferación de términos fusionados, más bien feos, pero plenos de significado, como "coopetencia" o la ya mencionada "glocalización".
} 


\section{VII \\ Las semillas del futuro Usar las oportunidades para prepararse a avanzar con la innovación tecnológica}

La elección de un camino basado en la utilización de los recursos naturales para la tecnologización de la producción en América Latina tiene una ventaja adicional preñada de posibilidades futuras.

La revolución de las TIC está ahora entrando en el período de despliegue, cuando su poder para aumentar la productividad y facilitar la innovación se difunde hacia todas las demás industrias. ${ }^{19}$ Es también el tiempo de gestación de la próxima revolución. Es muy posible que las industrias revolucionarias del futuro sean alguna combinación de biotecnología, nanotecnología, bioelectrónica, nuevos materiales y nuevas energías, en función de las rupturas tecnológicas que se puedan producir y probablemente moldeadas por la creciente preocupación ambiental.

Todas esas tecnologías pueden ser ubicadas en términos gruesos dentro de la categoría de industrias de procesos. Durante el período de gestación actual estas tenderán a desarrollarse en conexión con algunas de las industrias líderes existentes. Los nuevos materiales encontrarán cada vez más usos en las industrias de fabricación, la nanotecnología en superficies, electrónica, cosméticos, productos de salud y otros. También pueden influir en la producción de materias primas, como en el caso de las bacterias especiales para la lixiviación en la minería o para eliminar contaminantes y derrames; los aditivos químicos para agregar cualidades particulares a

\footnotetext{
${ }^{19}$ Dicho período es la segunda mitad del proceso de difusión de cada revolución tecnológica; se inicia luego de una gran burbuja financiera y su colapso y el consecuente reacomodo institucional que históricamente se ha caracterizado por la vuelta a un papel activo del Estado en la economía. Véase Pérez (2004, pp. 74-77, 107-112 y 175-188), y Pérez (2006).
}

la madera o servir como catalizadores en el refinamiento de petróleo y la petroquímica; los procesos para el control natural de plagas en la agricultura orgánica; y así sucesivamente. ${ }^{20}$

Si los ritmos históricos sirven como guía, la transición a esa nueva revolución podría ocurrir dentro de dos o tres décadas. Pero cualquiera sea el marco temporal, en América Latina puede comenzar ahora un proceso de elevación de sus capacidades a fin de alistarla para entrar en la próxima revolución utilizando sus actividades de exportación basadas en recursos naturales como plataforma para la innovación de avanzada y como fuente de financiamiento.

Es importante recordar que el Japón y los "tigres asiáticos" adquirieron su experiencia inicial ensamblando transistores y equipos electrónicos desde los años cincuenta y especialmente durante los sesenta y comienzos de los setenta. En esos tiempos, los componentes se usaban en los productos típicos de la revolución de la producción en masa: radios, televisores, tocadiscos, y otros, para los cuales las versiones portátiles constituían una innovación de expansión de mercados. Esto colocó a esos países en una posición ventajosa en términos de experiencia y capacidades cuando el microprocesador inauguró la revolución de las TIC. Algo similar puede tener lugar en América Latina la próxima vez, ahora no por casualidad, sino por una conducción consciente en esa dirección.

\footnotetext{
${ }^{20}$ Sobre el pensamiento estratégico en biotecnología en América Latina, véanse Hernández-Cuevas y Valenzuela (2004) y Gutman y otros (2006).
} 


\section{VIII \\ Una ventana de oportunidad pasajera Por qué también lo son las teorías sobre el desarrollo basado en los recursos naturales}

En esta propuesta se sostiene que los recursos naturales pueden, en las condiciones actuales y posiblemente por unos cuantos años, convertirse en la plataforma para dar un salto sostenible hacia el desarrollo. Ello implica que dichos recursos pueden convertirse en objeto de tecnologización para mejorar la calidad del perfil de las exportaciones y abrir oportunidades a porciones marginalizadas de la población. Sin embargo, las dudas tradicionales acerca de las posibilidades de alcanzar un desarrollo basado en los recursos naturales pueden llevar a cuestionar su viabilidad.

No deja de ser interesante advertir que la idea de la "maldición de los recursos naturales" es muy reciente y estuvo precedida por otras teorías con otros argumentos, a veces contradictorios en apariencia. En este trabajo se sostiene que las oportunidades cambian a medida que las diferentes revoluciones tecnológicas, con sus diferentes condiciones, emergen y se propagan.

Los economistas clásicos (y la opinión popular de su época) consideraban la posesión de recursos naturales como una ventaja para el desarrollo. La idea fue confirmada - y parcialmente inspirada - por países como Australia, Nueva Zelanda, el Canadá y la Argentina, que realizaron enormes saltos hacia adelante en el último cuarto del siglo XIX sobre la base de su minería, agricultura, la carne y las exportaciones de lana. Con ello financiaron sus puertos, aeropuertos, ferrocarriles y otras redes de infraestructura. Los recursos naturales también jugaron un papel positivo en la historia económica de los países escandinavos, así como en el Reino Unido y en los Estados Unidos.

La producción de recursos naturales comenzó a ser vista como una carga para el desarrollo después del período de instalación de la revolución de la producción en masa, cuando la industria de alta productividad se volvió insaciable en su necesidad de energía y materias primas baratas y cuando los materiales sintéticos comenzaron a reemplazar uno tras otro a los naturales. A mediados de la década de 1940, cuando se iniciaba el período de despliegue de la oleada de la producción en masa, ${ }^{21}$ tanto Prebisch como Singer vieron las brechas o diferenciales de

${ }^{21}$ Sobre los rasgos de los períodos de instalación y despliegue de cada oleada tecnológica, véase Pérez (2004 y 2009). precios entre las manufacturas y los materiales como un obstáculo para el desarrollo, como en efecto lo eran (Prebisch, 1951; Singer, 1950).

Más adelante se usó la noción de "enfermedad holandesa" para referirse a la manera como las exportaciones de gas (o petróleo) determinaban la tasa de cambio del país exportador dificultando las posibilidades de la manufactura. El concepto apareció cuando los precios de la energía se dispararon en la década de 1970 y fue usado por primera vez en un artículo de The Economist en 1977. Más recientemente, varias hipótesis sobre la "maldición de los recursos naturales" se pusieron de moda. Algunas veces se basaron en la experiencia de violencia, guerra y corrupción en las luchas internas por el control de fuentes de riqueza como los diamantes, el oro y el petróleo; otras se fundaron en el contraste entre el auge de los "tigres asiáticos" y la década perdida en África y América Latina.

Lo que aquí se sostiene es la existencia de ciertas particularidades en las condiciones actuales, diferentes de las que originaron las teorías anteriores, con las cuales se abre una ventana de oportunidad que abre paso al desarrollo basado en recursos naturales. Sin embargo, es solo una ventana y su duración puede ser relativamente breve, quizás de una década. ${ }^{22}$ Este juicio y los siguientes se basan en una valoración personal de las condiciones de viabilidad de esta propuesta.

Los siguientes son algunos de los factores que crean un contexto favorable para la iniciación ahora de la estrategia (2010-2012):

- En razón del balance oferta-demanda en el proceso de globalización, los niveles de precios de las materias primas tenderán a establecerse, casi con seguridad, por sobre los niveles históricos, aunque no desaparecerá la volatilidad. El nivel promedio

\footnotetext{
${ }^{22} \mathrm{El}$ tiempo disponible para iniciar una estrategia con posibilidades de éxito es diferente del tiempo en que esta estrategia puede rendir sus beneficios. La República de Corea entró en la industria de semiconductores y se convirtió en un líder en chips de memoria en el momento adecuado. Diez años después no habría sido posible; sin embargo, los beneficios de esa entrada temprana y el éxito alcanzado se han multiplicado en la medida en que esa experticia ha servido como plataforma para avances ulteriores en condiciones distintas.
} 
dependerá de las eventuales regulaciones financieras (para impedir la especulación con los commodities) y los reajustes de mercado.

- En la medida en que se obtengan beneficios extraordinarios, se facilitaría el llegar a negociaciones de suma positiva entre usuarios y proveedores y entre corporaciones y gobiernos con miras a utilizar parte de los beneficios e impuestos provenientes de los recursos naturales para financiar expansión de capacidad, procesamiento aguas abajo, tecnologización y mejora de las externalidades. Ello alimentaría la estrategia de desarrollo "desde arriba" (capital humano, servicios de alta tecnología, infraestructura, protección ambiental) y podría proporcionar los fondos para los proyectos de desarrollo "desde abajo".

- La crisis financiera de 2008 ha creado las condiciones para la aceptación de un papel más activo del Estado en la economía.

- Los cambios en la conciencia ambiental, la regulación y el comportamiento corporativo todavía son incipientes, pero comienzan a profundizarse. En particular, las industrias de procesos y las corporaciones extractivas se han demorado en adoptar el paradigma global de las TIC (en lo referente a incorporar a sus redes las capacidades locales), pero ya son observables los cambios en esa dirección.

- Las grandes empresas de servicios especializados están sobrecargadas y probablemente verán con buenos ojos el ingreso de aliados locales. Con el tiempo se habrán expandido para satisfacer la demanda y las firmas que no estén "dentro" de la red (como independientes o aliadas) encontrarán mucho más difícil el ingreso.

- Los competidores potenciales en este espacio estratégico (África, Rusia, Kazajstán y otros) apenas se están iniciando en caminos similares.

- Aquellos países o regiones que se logren convertir en competidores tempranos basados en estas tendencias serán quienes ejerzan el liderazgo, y la región capaz de atraer a las CG más dinámicas habrá adquirido ventajas decisivas.

Otro elemento que coloca a los recursos naturales en un camino dinámico es la manera como la dirección actual de la globalización está aumentando su impacto sobre el ambiente. Tanto los límites a la disponibilidad de recursos naturales como la amenaza del cambio climático van a convertirse en fuerzas clave para moldear los mercados y las tecnologías relacionadas con la energía, los materiales, el agua y los alimentos. Esto lleva a pensar que la escasez tenderá a elevar los precios de los productos naturales, convirtiendo su posesión en una ventaja aun mayor. Estos precios cambian junto con el incremento de los costos del transporte, que penalizará el traslado de las materias primas no procesadas en todo el mundo. Esto podría favorecer el procesamiento local. Al mismo tiempo, el aumento de los precios presiona a los usuarios a la utilización cada vez menor de esos materiales por unidad de producto. Esto favorecería a los materiales más finamente especificados, como es el caso de los sugeridos en esta estrategia.

El alza en los precios de los fletes conduce a reconsiderar la distribución geográfica de las actividades globalizadas y a tener en cuenta más factores al seleccionar entre ubicaciones locales, regionales o globales, dependiendo de las características de los productos y los componentes del costo. Esta tendencia abre unas oportunidades y cierra otras.

El tiempo que tardarán en generalizarse estas tendencias relacionadas con el ambiente puede ser muy corto, dependiendo de la intensidad de los efectos del calentamiento global y la regulación correspondiente. En cualquier caso, esto debería ser, desde el comienzo, un rasgo central de cualquier estrategia basada en los recursos naturales.

Finalmente, esta estrategia en su conjunto depende de un esfuerzo serio de compromiso activo y de fortalecimiento simultáneo del conocimiento y de la experiencia. El aprendizaje y la creación de capital humano toman tiempo (así como la mayoría de los proyectos de inversión). Ello supone que solo persistiendo cuanto antes en los objetivos planteados se colocará a los países de América Latina en un camino de crecimiento dinámico y a tiempo para seguirlo con éxito.

Si algo está claro es que si el aumento del ingreso por exportaciones de recursos naturales termina por convertirse en una fuente de crecimiento superficial y de incremento de las importaciones para el consumo, se habrá malgastado una oportunidad muy valiosa. 


\section{IX \\ La implementación de la visión Generación de consensos y marco institucional adecuado}

Ya hay muchas empresas latinoamericanas que participan en las redes de las CG, y algunas ya están construyendo sus propias redes globales. También hay muchas iniciativas gubernamentales para promover las asociaciones entre empresas pequeñas y medianas a fin de incrementar su competitividad. Algunos países han ido mucho más allá en uno u otro aspecto de las estrategias sugeridas aquí, así como en otras direcciones. La cuestión es saber si esos esfuerzos dispersos son suficientes, si podrán rendir el máximo beneficio potencial a las empresas y a la población de sus países y si las condiciones actuales permiten que se manifieste todo el potencial existente de creación de riqueza y de innovación. Un esfuerzo concentrado en una dirección acordada podría crear mayores externalidades para todos, logrando más rápidamente los resultados requeridos con tanta urgencia.

La disyuntiva "Estado o mercado" ya está obsoleta y resulta contraproducente. Ni la planificación central ni la libre acción del mercado resuelven todo. El terreno tiene más bien que estar sesgado en favor de las grandes mayorías y estimular vigorosamente el crecimiento y el éxito de los sectores potencialmente competitivos de la economía, reforzando más aún sus ventajas. La visión consensuada resultante de un debate muy informado e intenso, con participación de los empresarios, el gobierno y la sociedad en su conjunto, podría traer consigo el máximo de cohesión, la guía más efectiva, los instrumentos facilitadores y los resultados generales más beneficiosos para los participantes locales (y globales). El objetivo sería movilizar a toda la sociedad para que los diversos actores asuman sus iniciativas siguiendo caminos que, aunque distintos, convergen en una dirección general acordada.

Entre los posibles participantes en la mesa de discusiones están los gobiernos (desde el nacional hasta los locales), las CG, las grandes empresas locales, las EPIC, las pequeñas y medianas empresas (PYME), las universidades e institutos de investigación, las ONG relevantes, las empresas consultoras, los bancos y los organismos financieros internacionales, la diáspora (especialmente de negocios e intelectuales), los medios y la sociedad en su conjunto. El objetivo es convertir en realidad la promesa de todos los juegos de suma positiva: cada uno contribuye a aumentar el tamaño del pastel y así todos pueden incrementar los beneficios para sí.

El aprendizaje requerirá el compromiso de tres capas complementarias. Primero está el aprendizaje en el sector público, dado que solo una estructura gubernamental competente y bien articulada puede conducir una economía sofisticada moderna. Después está el sistema educativo, que deberá ser actualizado y adecuado en cuanto a los métodos y comportamientos, así como en el contenido técnico. Por último, está el aprendizaje del sector empresarial en la medida necesaria en cada caso para aumentar gradualmente sus capacidades innovativas. La colaboración entre los tres sectores -en conexión con sus contrapartes globales cuando sea necesario- hará posible tejer un "sistema nacional de innovación" fuerte. ${ }^{23}$

Conjuntamente con estos agentes, el aprendizaje deberá difundirse hacia la sociedad como opinión pública general, ayudado por la experiencia del trabajo y la educación, así como por los medios de comunicación, y contando también con el apoyo proactivo de diversas ONG y otras organizaciones.

En términos de políticas e instrumentos, las dos vertientes de la estrategia son muy distintas. Por lo tanto, el marco institucional también deberá ser dual.

En la visión de la autora, los criterios y métodos a utilizar en las dos mitades del modelo dual por ser tan diferentes requieren actitudes, comportamientos y competencias distintas e incluso instituciones e instrumentos de política diversos. Sin embargo, en ambos niveles el éxito va a requerir una cantidad suficiente de personal altamente entrenado, con las capacidades y dedicación adecuadas, así como suficiente poder para comprometer al gobierno junto con una clara comprensión de la nueva dinámica del mercado y las oportunidades que ofrece para el posicionamiento y la articulación favorables. Se requieren políticas audaces y una gran determinación para poder alcanzar el éxito. Por ello no se pueden excluir las barreras arancelarias temporales, ni los impuestos

\footnotetext{
${ }^{23}$ Esta concepción amplia del "sistema nacional de innovación”, donde se abarca a todos los agentes sociales involucrados en el proceso de innovación, fue introducida por Freeman (1987) y Lundvall (1988).
} 
y subsidios especiales para empujar con fuerza desde abajo con la finalidad de que la población empobrecida alcance condiciones de vida decentes.

Obviamente, hay grandes diferencias entre los países más grandes y poderosos y los más pequeños, tanto en términos del potencial de recursos como en las capacidades de implementación en los sectores público y privado. A este respecto, algunos organismos regionales y multilaterales podrán contribuir con apoyo técnico y financiero, y los países más poderosos podrán establecer mecanismos para servir como polos dinámicos ayudando a halar a los más pequeños.

Más allá de los tamaños relativos y los niveles previos de desarrollo, hay muchos otros factores relacionados con el poder y capaces de influir en la viabilidad de la estrategia general, pudiendo dar como resultado diferencias incluso más pronunciadas entre países. Las condiciones de la producción y de los mercados son muy diferentes para las empresas locales y las extranjeras, para los minerales y la energía o la agricultura, para la ganadería, silvicultura y acuicultura, en los casos donde la propiedad y el control de la producción están concentrados o dispersos, o en aquellos de mayor concentración o disgregación del comercio y los mercados internacionales. Las condiciones también serán distintas de acuerdo con la proporción de la cadena de valor que esté (o pueda estar) en el territorio, según el mayor o menor peso relativo de las actividades intensivas en conocimiento versus las de rutina, y así sucesivamente. La diversidad de condiciones definirá la necesidad de políticas adecuadas en cada caso, aun teniendo el mismo objetivo general.

Sin embargo, la pregunta crucial que puede construir o destruir la estrategia es si hay fortaleza o potencial en las instituciones para promover consensos, aplicar medidas audaces y mantener las políticas, o aplicar las regulaciones o impuestos y evitar el fracaso de la "captura" o de la corrupción o de ambos.

Pero no hay que hacerse ilusiones. Una estrategia como esta encontrará resistencia de ambos lados del espectro ideológico y político. Habrá objeciones tanto acerca del papel del Estado como sobre el papel de las CG en el proceso; habrá dudas acerca del potencial de crecimiento basado en los recursos naturales, así como sobre las capacidades locales de innovación. Por ello, habría que garantizar que los debates fuesen enriquecidos con abundante información. Mientras más conocimiento se tenga sobre lo que está ocurriendo en otras partes del mundo (e incluso en la misma América Latina) en innovación y cooperación y en el desarrollo de nichos en recursos naturales, menos prejuicios habrá que enfrentar y desmontar.

En conclusión, en este trabajo se ha sostenido la necesidad de no desperdiciar una ventana de oportunidad existente en la actualidad, que es particularmente adecuada para la dotación en recursos naturales y la experiencia histórica de América Latina. Esta ventana consiste en el aprovechamiento de la hipersegmentación de los mercados, las actividades y las tecnologías típicas del paradigma de las TIC y su aplicación aun más profunda en las industrias de procesos basadas en recursos naturales. Esto sería facilitado por el probable aumento de los niveles promedio de precios de esos recursos a causa del crecimiento globalizado. Utilizando una parte del incremento de los ingresos para mejorar tecnológicamente el perfil de las exportaciones y fomentar las capacidades de la población para crear riqueza, la región puede especializarse en materiales hechos a la medida del cliente, alimentos sofisticados y otros productos naturales, mientras se prepara para un buen posicionamiento en la próxima revolución tecnológica. La estrategia puede servir tanto para la competencia en la punta de los mercados globales, como para sacar a la población de la pobreza mediante la creación de aglomeraciones productivas (clusters) orientadas a especializaciones de "nicho" a todo lo largo y ancho del territorio.

Cada vez más se está practicando y entendiendo la innovación en todos los aspectos de los negocios como el camino hacia el éxito. Ha llegado la hora de hacer otro tanto en el sector público como agente y facilitador del cambio, repensando, reorganizando e innovando para el máximo beneficio de la población. Por supuesto, el éxito de una estrategia como la propuesta dependerá en buena medida de la adopción de liderazgos con determinación y de la más amplia creatividad institucional. 


\section{Bibliografía}

Bazan, L. y L. Navas-Aleman (2004), "The underground revolution in the Sinos Valley: a comparison of upgrading in global and national value chains", Local Enterprises in the Global Economy, Hubert Schmitz (comp.), Cheltenham, Edward Elgar.

Bell, Martin (2006), "Time and technological learning in industrializing countries: how long does it take? How fast is it moving (if at all?)", International Journal of Technology Management, vol. 36, $N^{\circ} 1 / 2 / 3$, Londres, Inderscience Publishers.

Berger, Suzanne (2006), How We Compete: What Companies Around the World Are Doing to Make It In Today's Global Economy, Nueva York, Currency-Doubleday.

Bisang, Roberto y otros (comps.) (2006), Biotecnología y desarrollo, Buenos Aires, Prometeo.

CEPAL (Comisión Económica para América Latina y el Caribe) (2008), La transformación productiva 20 años después: viejos problemas, nuevas oportunidades (LC/G.2367(SES.32/3)), Santiago de Chile.

(1990), Transformación productiva con equidad: la tarea prioritaria del desarrollo de América Latina y el Caribe en los años noventa (LC/G.1601(SES.23/4)), Santiago de Chile.

Dutrénit, G. (2006), "Instability of the technology strategy and building of the first strategic capabilities in a large Mexican firm", International Journal of Technology Management, vol. 36, $N^{\circ} 1 / 2 / 3$, Londres, Inderscience Publishers.

Dutrénit, G. y A.O. Vera-Cruz (2007), "Triggers of the technological capability accumulation in MNCs' subsidiaries: the maquilas in Mexico", International Journal of Technology and Globalisation, vol. 3, No 2/3, Londres, Inderscience Publishers.

Ernst, Dieter (2000), "Global production networks and the changing geography of innovations systems: implications for countries", East-West Center Working Paper Economics Series, No 9, Honolulu, East-West Center, noviembre.

Ernst, Dieter y Linsu Kim (2002), "Global production networks, information technology and knowledge diffusion", Industry and Innovation, vol. 9, № 3, Londres, Routledge.

Fajnzylber, Fernando (1990), "Industrialización en América Latina: de la 'caja negra' al 'casillero vacío', serie Cuadernos de la CEPAL, N ${ }^{\circ} 60$ (LC/G.1534/Rev.1-P), Santiago de Chile, Comisión Económica para América Latina y el Caribe (CEPAL). Publicación de las Naciones Unidas, $\mathrm{N}^{\circ}$ de venta: S.89.II.G.5.

Freeman, Christopher (1987), Technology Policy and Economic Performance: Lessons from Japan, Londres, Pinter.

Garten, Jeffrey E. (comp.) (2000), World View: Global Strategies for the New Economy, Boston, Harvard Business Press.

Gereffi, G. (1994), "The organization of buyer-driven global commodity chains: how U.S. retailers shape overseas production networks", Commodity Chains and Global Capitalism, G. Gereffi y M. Korzeniewicz (comps.), Londres, Praeger.

Gereffi, G., J. Humphrey y T. Sturgeon (2005), "The governance of global value chains", Review of International Political Economy, vol. 12, $\mathrm{N}^{\mathrm{o}} 1$, Londres, Routledge.

Gereffi, G. y Raphael Kaplinsky (comps.) (2001), "The value of value chains: spreading the gains from globalization", IDs Bulletin, vol. 32, $\mathrm{N}^{\mathrm{o}}$ 3, Brighton, Institute of Development Studies, julio.

Giuliani, E., C. Pietrobelli y R. Rabellotti (2005), "Upgrading in global value chains: lessons from Latin America clusters", World Development, vol. 33, № 4, Amsterdam, Elsevier.

Gurlit, Wieland, Eduardo Mencarini y Ricardo Montealto (2007), "Weighing the risks in South American basic materials", The McKinsey Quarterly, McKinsey \& Company, agosto.

Gutman, Graciela y otros (2006), "Una visión de conjunto. Las biotecnologías en Argentina: situación actual y potencialidades", Biotecnología y desarrollo, Roberto Bisang y otros (comps.), Buenos Aires, Prometeo.
Hernández-Cuevas, C. y Pablo Valenzuela (2004), "Strategies to capture biotechnology opportunities in Chile", Electronic Journal of Biotechnology, vol. 7, $\mathrm{N}^{\circ}$ 2, Valparaíso, Pontificia Universidad Católica de Valparaíso.

Hobday, Michael, Andrew Davies y Andrea Prencipe (2006), "Systems integration: a core capability of the modern corporation", Industrial and Corporate Change, vol. 14, $\mathrm{N}^{\circ}$ 6, Oxford, Oxford University Press.

Humphrey, John y Hubert Schmitz (2004), "Governance in global value chains", Local Enterprises in the Global Economy: Issues of Governance and Upgrading, $\mathrm{H}$. Schmitz, Cheltenham, Edward Elgar.

Infante, R. y O. Sunkel (2009), "Chile: hacia un desarrollo inclusivo", Revista de la CEPAL, No 97 (LC/G.2400-P), Santiago de Chile, abril.

Kaplinsky, Raphael (2005), Globalisation, Poverty and Inequality: Between a Rock and a Hard Place, Cambridge, Polity Press.

Kindleberger, Charles P. (1991), Manías, pánicos y cracs: historia de las crisis financieras, Barcelona, Editorial Ariel.

Lundvall, Bengt-Ake (1988), "Innovation as an interactive process: from user-producer interaction to the national systems of innovation", Technical Change and Economic Theory, G. Dosi y otros, Londres, Pinter.

Marin, Anabel (2007), "Thinking locally: new approaches to foreign direct investment" [en línea] http://web.scidev.net/ en/policy-briefs/thinking-locally-new-approaches-to-foreigndirect-html.

Nadvi, K. y Hubert Schmitz (comps.) (1999), "Industrial clusters in developing countries", World Development, vol. 27, $\mathrm{N}^{\circ}$ 9, número especial, Amsterdam, Elsevier.

Pérez, Carlota (2009), "La otra globalización: los retos del colapso financiero", Problemas del desarrollo, vol. 40, № 157, México, D.F., Universidad Nacional Autónoma de México.

(2006), "Re-specialisation and the deployment of the ICT paradigm: an essay on the present challenges of globalisation", The Future of the Information Society in Europe: Contributions to the Debate, R. Compano y otros, Technical Report EUR22353EN, Comisión Europea, noviembre [en línea] http://www.carlotaperez.org/papers/PEREZ_Respecialisation_ and_ICTparadigm.pdf.

(2004), Revoluciones tecnológicas y capital financiero: la dinámica de las grandes burbujas financieras y las épocas de bonanza, México, D.F., Siglo XXI.

(2001), "El cambio tecnológico y las oportunidades de desarrollo como blanco móvil", Revista de la CEPAL, $\mathrm{N}^{\circ} 75$ (LC/G.2150-P), Santiago de Chile, diciembre.

(1996), "La modernización industrial en América Latina y la herencia de la sustitución de importaciones", Comercio exterior, vol. 46, No 5, mayo, México, D.F. Banco Nacional de Comercio Exterior (BANCOMEXT) [en línea] http://www.carlotaperez.org/ Articulos/modernizyherencia-ISILA\%20t.htm

PNUD (Programa de las Naciones Unidas para el Desarrollo) (2007), Informe sobre desarrollo humano 2007-2008, Nueva York.

Prahalad, C.K. (2004), The Fortune at the Bottom of the Pyramid. Eradicating Poverty through Profits, Philadelphia, Wharton School Publishing.

Prahalad, C.K. y Gary Hamel (1990), "The core competence of the corporation”, Harvard Business Review, vol. 68, №3, Boston, Harvard Business Publishing, mayo-junio.

Prebisch, Raúl (1988), Pensamiento y obra, Buenos Aires, Editorial Tesis.

(1951), "Crecimiento, desequilibrio y disparidades: interpretación del proceso de desarrollo económico", Estudio económico de América Latina 1949 (E/CN.12/164/REV.1), 
Nueva York, Naciones Unidas. Publicación de las Naciones Unidas, $\mathrm{N}^{\mathrm{o}}$ de venta. 51.II.G.1.

Prencipe, Andrea, Andrew Davies y Michael Hobday (comps.) (2003), The Business of Systems Integration, Nueva York, Oxford University Press.

Schmitz, Hubert (comp.) (2004), Local Enterprises in the Global Economy, Cheltenham, Edward Elgar.

Singer, Hans (1950), "The distribution of gains between investing and borrowing countries", American Economic Review, vol. 40, № 2, Nashville, Tennessee, American Economic Association.

Vera-Cruz, A.O. (2006), "Firms' culture and technological behaviour: the case of two breweries in Mexico", International Journal of Technology Management, vol. 36, N $\mathrm{N}^{\mathrm{o}}$ 1/2/3, Londres, Inderscience Publishers.

Walker, M. y P. Jourdan (2003), "Resource-based sustainable development: an alternative approach to industrialisation in South Africa", Minerals \& Energy. Raw Materials Report, vol. 18, $\mathrm{N}^{\circ} 3$, Londres, Routledge.

Warhurst, Alyson (2005), "Future roles of business in society: the expanding boundaries of corporate responsibility and a compelling case for partnership", Futures, $\mathrm{N}^{\mathrm{o}} 37, \mathrm{~N}^{\mathrm{o}} 2-3$, Amsterdam, Elsevier, marzo-abril.

Woodward, Joan (1965), Industrial Organization: Theory and Practice, Oxford, Oxford University Press. 